\title{
Blood glucose testing by drivers with diabetes: a survey of glucose meter users
}

\author{
BERIT INKSTER, ${ }^{1}$ DEAN POOLEY, ${ }^{2}$ HELEN DE SAXE, ${ }^{2}$ MANSOOR ASHRAF, ${ }^{2}$ BRIAN M FRIER ${ }^{1}$
}

\begin{abstract}
Aims: To assess knowledge of, and adherence to, current driving recommendations in drivers with insulin- or tablettreated diabetes.

Methods: People on a large customer database were contacted by ordinary mail $(73,000)$ or email $(95,000)$ and invited to complete a 17-point survey about diabetes and driving. Only drivers with diabetes receiving treatment with glucose-lowering medications and/or insulin were included. Data from respondents were analysed by an independent research company.

Results: The response rate was $14 \%(n=23,742)$, of whom 16,172 ( $10 \%$ of the total database) were eligible for inclusion in the analysis. Only $66 \%$ of eligible participants were fully cognisant of driving safety recommendations. Adherence to blood glucose testing before driving and during long journeys was limited in insulin users at $47 \%$ and $41 \%$ respectively. Hypoglycaemia while driving was experienced by $13.1 \%$ of insulin users and $1.5 \%$ on tablets; 203 $(\mathbf{1 . 3} \%)$ of drivers surveyed reported that a motor vehicle accident had been a consequence of hypoglycaemia.

Conclusions: Drivers with diabetes appear to have a significant deficit in knowledge about driving safety recommendations and glucose monitoring. This may impose a greater risk of hypoglycaemia while driving, and enhance accident risk.
\end{abstract}

Br J Diabetes Vasc Dis 2015;15:20-23

Key words: diabetes, driving, DVLA, insulin

\section{Introduction}

Diabetes is considered to be a prospective disability with respect to medical fitness to drive, which in the UK is reviewed at intervals of 1-3 years in drivers who are treated with insulin. The principal hazard to driving safety is the development of hypoglycaemia while driving. In the UK the national licensing authority, the DVLA, recommends that drivers measure their blood glucose

Department of Diabetes, Royal Infirmary of Edinburgh, Edinburgh, UK 2 Roche Diagnostics Limited, Charles Avenue, Burgess Hill, West Sussex, UK

Address for correspondence: Dr Berit Inkster

Department of Diabetes, Royal Infirmary of Edinburgh, Edinburgh

EH16 4SA, UK.

Tel: +44(0)7763069184

E-mail: binkster@doctors.org.uk

http://dx.doi.org/10.15277/bjdvd.2015.003

\author{
Abbreviations and acronyms \\ DVLA Driver and Vehicle Licensing Agency
}

before driving and at intervals during longer journeys. ${ }^{1}$ This practice is not enforceable and previous small surveys of insulintreated drivers attending specialist outpatient clinics have indicated that very few people measure blood glucose routinely in relation to driving. 2,3 Drivers in the UK who have type 2 diabetes treated with oral glucose-lowering medications do not have to declare that they have diabetes for licensing, but evidence from insurance statistics suggests some may suffer driving mishaps as a consequence of hypoglycaemia, ${ }^{4}$ although this is probably much less common than in drivers with type 1 diabetes. ${ }^{5}$ It would therefore be prudent for drivers taking an insulin secretagogue, (sulfonylureas and glinides), to monitor blood glucose in relation to driving. In the European Union, blood glucose monitoring at times relevant to driving is now a requirement for professional drivers with insulin-treated diabetes who hold a Group 2 driving licence. ${ }^{6}$ Failure to test blood glucose before driving could have legal consequences in the event of a hypoglycaemia-induced driving accident.

It is important that drivers with insulin-treated diabetes are fully cognisant of the recommendations to test blood glucose when driving and their obligation to report episodes of severe hypoglycaemia and motor vehicle accidents caused by hypoglycaemia. Unfortunately, many drivers with diabetes do not adhere to recommended practice and may not know that it is unsafe to drive when their blood glucose is below $4.0 \mathrm{mmol} / \mathrm{l} .{ }^{2,7}$ Many healthcare professionals who advise people with diabetes appear to have a limited knowledge of the recommendations for safe driving, ${ }^{8}$ and many people with diabetes claim to have never discussed driving with their healthcare provider. ${ }^{5}$

The knowledge of drivers with diabetes of recommendations for blood glucose testing in relation to driving and their current practice were ascertained in a large email and postal survey, in which the frequencies of hypoglycaemia being experienced in relation to driving and to driving accidents were also documented.

\section{Subjects}

British drivers with types 1 and 2 diabetes who were using AccuChek ${ }^{\circledR}$ glucose meters (Roche) were registered on a UK customer database held by the company, which included those who had previously contacted the Accu-Chek ${ }^{\circledR}$ Careline or website to seek advice or assistance. The database also included interested individuals who had provided contact details for surveys and 
promotions, or who had requested product information such as the eReach online customer magazine (Roche Diagnostics Ltd). The database also included people residing in the Republic of Ireland and in UK sovereign territories.

The age of people in the database ranged from $<17$ years $(2 \%$ of total) to people aged over 76 years (18\%). Both sexes were equally represented; the gender of $5 \%$ had not been recorded.

Participants were informed that all personal information would be strictly confidential, and that published results would be anonymised. Roche Diagnostics Ltd abides by the Data Protection Act 1998 and is registered as a data controller under this Act.

\section{Methods}

A retrospective survey was undertaken in the UK of drivers with types 1 and 2 diabetes. The survey was designed to be quick and easy to complete to try to maximise recruitment, and contained 17 multiple choice questions. Most questions had two or three possible responses (for example: 'yes', 'no', or 'partly'). It was distributed in May 2011 to 168,000 people who were registered on the Accu-Chek ${ }^{\circledast}$ database; by email $(95,000)$ or by ordinary mail $(73,000)$. As an incentive to respond, respondents were offered entry to a prize draw if they replied within a set time limit. Only the responses from drivers with diabetes who were on treatment (self-reported) with insulin or tablets have been analysed. Non-drivers and drivers treated with diet alone were excluded.

Not all participants answered every question, so analyses were limited to available responses within each question, and did not take into account missing responses. The response rate per question ranged from $99.99 \%(n=16,170)$ to $92.02 \%(n=14,881)$. Raw data were analysed by Research Plus ${ }^{\mathrm{TM}}$, an independent company providing research services. The survey was designed and conducted by Roche Diagnostics Ltd, with no input from BI and BMF; the manuscript was written retrospectively using the available data.

\section{Results}

\section{Participants}

Responses from 23,742 individuals were received (14\% of total approached), 18,268 (77\%) of whom were drivers. Of these, individuals who were treated with insulin and/or tablets were
Figure 1. Response to questions about testing before and during driving in insulin users

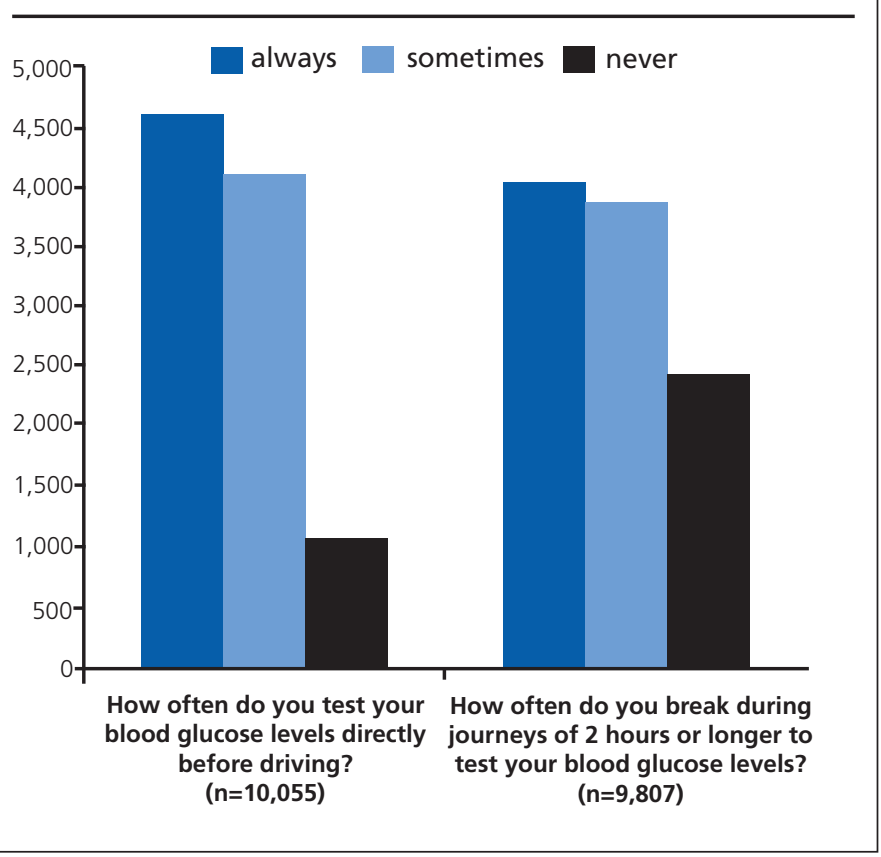

included in the analysis ( $n=16,172,10 \%$ of total mail shot, $68 \%$ of responders, $89 \%$ of drivers). Those included were similar in age distribution to the database, with an age range of $<17$ years to $>76$ years. Most were aged between 46 and 75 years $(66 \%$, $n=10,674)$. They were predominantly male $(64 \%, n=10,350)$; gender was unknown in $8 \%(n=1,294)$. More than half $(63 \%$, $n=10,188$ ) were receiving treatment with insulin. Driving was essential for employment in 4,156 respondents (26\%).

\section{Awareness of and adherence to DVLA guidelines}

When insulin-treated drivers were asked: "Are you aware of the DVLA guidelines regarding blood glucose monitoring and driving?" $74 \%(7,504)$ stated they were aware, while $15 \%(1,533)$ were partly aware and $11 \%(1,117)$ were not aware of the recommendations. When asked about the specific recommendation of measuring blood glucose before driving, and testing during a journey of more than 2 hours, fewer than half of the insulin-treated drivers

Table 1 Reasons for not testing regularly when driving

\begin{tabular}{|c|c|c|c|c|}
\hline \multirow{2}{*}{$\begin{array}{l}\text { Reason } \\
\text { (Given as options rather than free text)* }\end{array}$} & \multicolumn{2}{|c|}{ Whole cohort $(n=14,881)$} & \multicolumn{2}{|c|}{ Insulin users $(n=9,354)$} \\
\hline & n & $\%$ & n & $\%$ \\
\hline I always test regularly when driving & 4,464 & 30 & 3,929 & 42 \\
\hline Requires a suitable place & 2,530 & 17 & 1,871 & 20 \\
\hline It is fiddly and inconvenient in a vehicle & 2,381 & 16 & 1,590 & 17 \\
\hline Not having test strips or lancets to hand & 2,232 & 15 & 1,029 & 11 \\
\hline Disposal of used test strips or lancet & 1,190 & 8 & 748 & 8 \\
\hline It takes too long & 446 & 3 & 281 & 3 \\
\hline It is painful & 149 & 1 & 94 & 1 \\
\hline Other & 5,060 & 34 & 2,245 & 24 \\
\hline
\end{tabular}


Table 2 Characteristics of participants who reported a driving accident as a result of hypoglycaemia

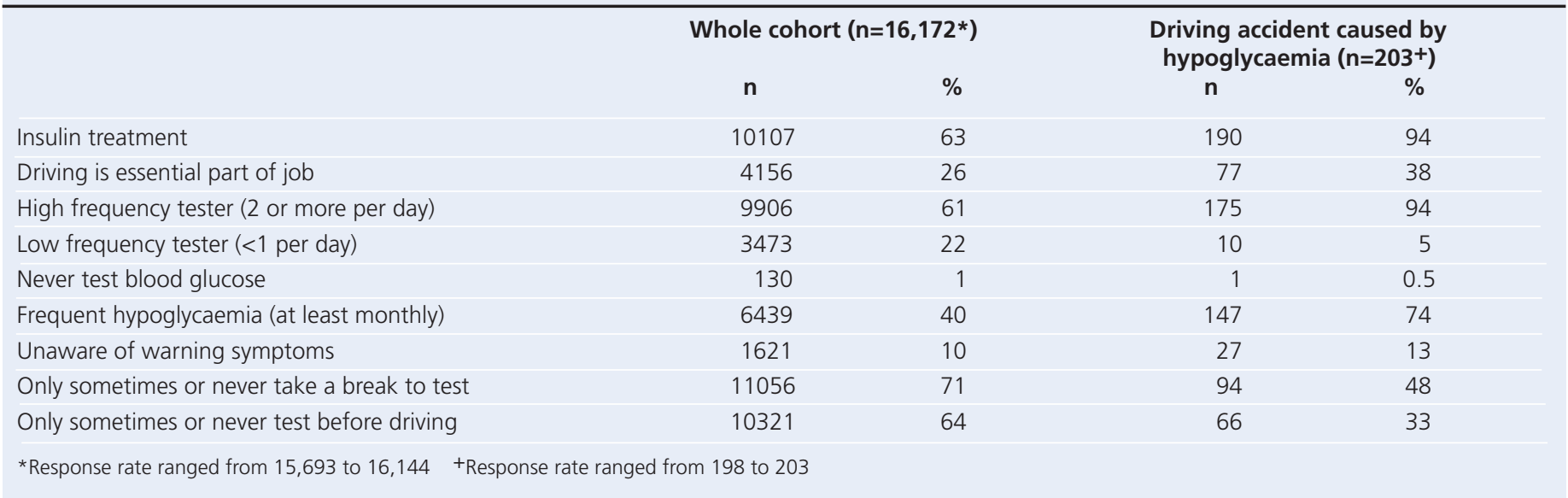

answered 'always' to these questions (see Figure 1). Only $72 \%$ $(11,605)$ of the survey had discussed the risks of hypoglycaemia and driving with a health care professional involved with their treatment (either in detail or briefly). This was higher $(83 \%, n=8,358)$ among insulin-treated drivers.

Perceived barriers of the participants to undertake regular blood glucose testing in relation to driving are shown in Table 1.
Available responses included 'I always test regularly when driving', 'other', or six possible reasons for not testing; participants could give multiple responses if desired. The most common response in those who did not always test was 'other'.

\section{Hypoglycaemia and driving}

With respect to the frequency of hypoglycaemia, the options

Table 3 The deficiencies in safe driving practice in relation to the DVLA recommendations are highlighted, with key points of advice that should be conveyed to drivers with diabetes

\section{DVLA recommendations for safe driving practice with diabetes ${ }^{1}$}

Always carry a glucose meter and blood glucose strips. Always keep an emergency supply of fast-acting carbohydrate such as glucose tablets or sweets within easy reach in the vehicle.

Particular care should be taken during changes of insulin regimens, changes of lifestyle, exercise, travel and pregnancy.

Take regular meals, snacks and rest periods on long journeys.

Check blood glucose before the first journey and every two hours while driving. If less than $4.0 \mathrm{mmol} / \mathrm{l}$ or the driver feels hypoglycaemic, do not drive.

If hypoglycaemia develops while driving, stop the vehicle as soon as possible. The engine must be switched off, keys removed from the ignition and the driver should move from the driver's seat. Driving must not be restarted until 45 min after blood glucose has returned to normal.

The driver should carry personal identification to show that they have diabetes in case of injury in a road traffic accident.

\section{Relevant survey findings}

One in 10 of the drivers with diabetes who were surveyed was not aware of the DVLA recommendations for safe driving practice.

One in four of the insulin-treated drivers in this survey were NOT aware of the DVLA guidelines regarding blood glucose monitoring and driving. Only half of the insulin-treated drivers always tested blood glucose before driving; $41 \%$ tested when undertaking a journey of 2 hours or more.

Hypoglycaemia while driving was reported by $13 \%$ of insulin-treated drivers and $1.5 \%$ of drivers taking oral antidiabetic medications.

$1.3 \%$ of drivers reported having had a motor vehicle accident as a direct consequence of developing hypoglycaemia, most of whom were receiving treatment with insulin.

\section{Key points of advice for drivers with diabetes}

Attention should be drawn to the existence of these DVLA recommendations for safe driving practice; copies of the DVLA leaflet could be available for distribution to individual drivers to reinforce this practical advice.

The importance and value of blood glucose monitoring in relation to driving should be highlighted, for journeys of any length. Drivers with diabetes on glucose-lowering therapies (insulin and sulfonylureas) should be advised always to carry their glucose meter in the vehicle.

Advice should be given about carrying readily accessible glucose in the vehicle in both fast-acting and complex forms.

Personal identification should be carried at all times by people treated with insulin. 


\section{Key messages}

- A knowledge deficit about safe driving practice is present in many drivers with diabetes

- Hypoglycaemia while driving is commonplace, particularly in those treated with insulin

- Many reasons are offered for not testing blood glucose at times relevant to driving and this failure of practice needs to be addressed by health care providers

were given of: 'never', 'daily', 'weekly' or 'monthly'. A total of $5,560(56 \%)$ of insulin users and $725(12 \%)$ of tablet users reported suffering from hypoglycaemia at least monthly. This had occurred while driving in 1,324 (13.1\%) of insulin users and 92 $(1.5 \%)$ of tablet users. In those who experienced hypoglycaemia at least monthly, 1,144 (20.7\%) of insulin users and 62 (8.7\%) of tablet-treated subjects had experienced hypoglycaemia while driving.

Of the respondents who were drivers, 203 (1.3\%) reported having had a motor vehicle accident as a direct consequence of developing hypoglycaemia; 190 (94\%) of these were receiving treatment with insulin. Compared to other responders these drivers experienced more frequent hypoglycaemia, were more likely to report diminished or absent awareness of hypoglycaemia, and were more likely to report that driving was essential for their employment (Table 2). Their annual mileage was not recorded.

\section{Discussion and conclusions}

The present survey has highlighted that many drivers with diabetes are unfamiliar with, or only partly cognisant of, the recommendations that are issued to all drivers with diabetes by the DVLA regarding measures relevant to safe driving practice. Less than half of insulin-treated drivers always adhered to these measures. These findings in a nationwide survey are similar to those of previous smaller local surveys, 2,8,9 and demonstrate the need to ensure that people with diabetes receive education about driving safety and the importance of measuring blood glucose before and during driving (Table 3).

The survey has some weaknesses, particularly in its design. The survey population was not fully characterised, and may not have been representative of all drivers with diabetes through self-selection, involving participants who had an interest in blood glucose monitoring using a meter, and/or an interest in driving and diabetes. Hypoglycaemia, diabetes type, and treatment were all based on self-reporting and no definitions were provided for the survey. The simple format of the survey questionnaire, with a small number of closed questions, limited the scope of the analysis. Despite these deficiencies, this is one of the largest surveys of blood glucose monitoring and driving that has been conducted and included people with diabetes attending both primary and secondary care clinics, whose responses are of interest even if the figures obtained may be less accurate than a more formal prospective study.

The present survey explored possible barriers to blood glucose testing in relation to driving, and many respondents selected several of the suggested reasons. Previous studies have indicated that other barriers may include restrictions on test strip provision, ${ }^{9}$ and a feeling that the advice was unreasonable or inconvenient. ${ }^{3}$ It is essential that reasons causing reluctance to measure blood glucose are addressed. Information on DVLA recommendations and their rationale should be provided, and technology which allows more rapid testing, or assists with disposal of used test strips and needles should be considered.

Conflict of interest The manuscript was composed from the data provided by Roche Diagnostics Ltd., but without input or alteration from Roche Diagnostics Ltd. Roche has provided funding for BI to attend an international diabetes educational meeting.

DP, HS, and MA work for Roche Diagnostics Ltd. marketing department. BMF has served on a medical advisory board for Roche Diagnostics Ltd.

Acknowledgements The survey was conducted and funded by Roche Diagnostics Ltd, which manufactures Accu-Chek ${ }^{\circledR}$ blood glucose meters.

\section{References}

1. Driver and Vehicle Licensing Authority (DVLA). For medical practitioners. At a glance guide to the current medical standards of fitness to drive May 2012 incorporating August/October 2012 amendments. Drivers Medical Group, DVLA, Swansea, 2012. Available from: http://www.dft.gov.uk/dvla/medical/ataglance.aspx.

2. Graveling AJ, Warren RE, Frier BM. Hypoglycaemia and driving in people with insulin-treated diabetes: adherence to recommendations for avoidance. Diabet Med 2004;21:1014-19. http://dx.doi.org/10.1111/j.1464-5491.2004.01288.x

3. Bodansky DMS, Bodansky HJ. Understanding, knowledge and attitudes towards current UK driving advice in insulin treated diabetic patients. Prac Diabet Int 2009;26:318-321iii.

4. Signorovitch JE, Macaulay D, Diener M, et al. Hypoglycaemia and accident risk in people with type 2 diabetes mellitus treated with non-insulin antidiabetes drugs. Diabetes Obes Metab 2013;15:335-41. http://dx.doi.org/10.1111/dom.12031

5. Cox DJ, Penberthy JK, Zrebiec J, et al. Diabetes and driving mishaps: frequency and correlations from a multinational survey. Diabetes Care 2003;26:2329-34. http://dx.doi.org/10.2337/diacare.26.8.2329

6. Inkster B, Frier BM. Diabetes and driving. Diabetes Obes Metab 2013;15:775-83. http://dx.doi.org/10.1111/dom.12071

7. Clarke WL, Cox DJ, Gonder-Frederick LA, et al. Hypoglycemia and the decision to drive a motor vehicle by persons with diabetes. JAMA 1999 25;282:750-4. http://dx.doi.org/10.1001/jama.282.8.750

8. Watson WA, Currie T, Lemon JS, et al. Driving and insulin treated diabetes: who knows the rules and recommendations? Pract Diabet Int 2007;24:201-06. http://dx.doi.org/10.1002/pdi.1097

9. Jackson-Koku G, Morrison G, Morrison CL, et al. Insulin-treated diabetes and driving: what is the patient's knowledge of current regulations? $\mathrm{Br}$ J Diabet Vasc Dis 2010;10:31-4.

http://dx.doi.org/10.1177/1474651409355115 